\title{
Implementasi Sistem Telemetri Pendeteksi Musuh Pada Drone S2GA Menggunakan Sensor PIR Berbasis Arduino
}

\author{
Wibi Bagas Ardytyan \\ Fakultas Teknik Telekomunikasi militer \\ Program Studi Telekomunikasi \\ Politeknik Angkatan Darat Batu, \\ Malang, Indonesia \\ Komd4205@gmail.com
}

\author{
Eko Kuncoro \\ Fakultas Teknik Telekomunikasi militer \\ Program Studi Telekomunikasi \\ Politeknik Angkatan Darat Batu, \\ Malang, Indonesia \\ Ekokoncoro@gmail.com
}

\author{
Yudhi Darmawan \\ Fakultas Teknik Telekomunikasi militer \\ Program Studi Telekomunikasi \\ Politeknik Angkatan Darat Batu, \\ Malang, Indonesia \\ Yuhdipk8@gmail.com
}

\begin{abstract}
Penelitian ini dilakukan pada saat drone mode autonomous untuk melakukan pengintaian saat melalui point yang sudah ditandai sebagai cekpoint sensor PIR akan menangkap radiasi infrared pada objek yang di lewati jika menangkap radiasi yang berwarna merah kekuningan maka dapat dianggap musuh. Rangkaian alat pendeteksi tersebut terdiri dari beberapa unit yaitu transmitter dan receiver. Transmitter di rangkaian tersebut berupa sensor PIR HCSR501, buzzer dan transceiver. Untuk pemrosesan progam mengunakan arduino uno .lalu hasil pendeteksian musuh kemudian dikirimkan ke unit repeater. Dari penelitian yang ini, sensor PIR mendapatkan jarak maksimum mendeteksi manusia dengan jarak $12 \mathrm{~m}$. sistem telemetri yang digunakam memiliki jangkauan maksimum $1 \mathrm{~km}$ ketika tanpa halangan dan $400 \mathrm{~m}$ ketika adanya penghalang dengan kondisi yang tidak hujan. Dan drone S2GA memiliki jarak maksimum horizontal $835 \mathrm{~m}$ dan jarak maksimum vertical $150 \mathrm{~m}$. hasil pengujian tersebut menampilkan pengiriman data hasil pendeteksi musuh menggunakan telemetri menghasilkan hasil jarak maksimum $620 \mathrm{~m}$ dengan ketinggian $40 \mathrm{~m}$.
\end{abstract}

Kata Kunci- Drone Quadcopter, Telemetri, , PIR HCSR501, Arduino

\section{Pendahuluan (Heading 1)}

Drone pada era industri 4.0 banyak memiliki kegunaan bagi manusia dalam berbagai bidang, saat ini drone digunakan dalam berbagai hal seperti pengambilan gambar wilayah, penyiraman dalam bidang pertanian, dan keperluan militer dalam melakukan tugasnya. Drone juga banyak digunakan perguruan tinggi untuk meneliti guna pengujian dan pengembangan yang dapat membantu manusia dalam melakukan pekerjaannya. Selain dalam perkembangan drone pada saat ini, dilihat dari kegunaan tersebut drone mampu membantu pekerjaan yang jika di kerjakan oleh manusia memakan waktu yang lama, selain itu drone mempunyai kelebihan yang mudah di kendalikan, dapat terbang cepat atau lambat sesuai kemauan pengguna. Banyak drone pada saat ini sudah di lengkapi dengan kamera yang berfungsi untuk melihat keadaan yang susah dijangkau oleh mata manusia atau tidak dapat dilihat secara langsung, drone sendiri mempunyai berbagai variasi dalam hal bentuk, salah satunya adalah berbentuk quadcopter[1]. Quadcopter ini sendiri merupakan drone yang menggunakan empat baling - baling dan empat motor sebagai penggerak. Dengan empat motor yang terdapat pada drone quadcopter tersebut drone ini akan lebih stabil dalam terbang dan dapat digunakan dalam berbagai kondisi. Pemanfaatan drone dalam memonitoring sudah banyak dilakukan dan sudah banyak hasil positif yang di berikan dalam pemanfaatan drone quadcopter karena drone quadcopter dapat melihat lebih luas.dan ketinggian bias di atur sesuai dengan kebutuhan. Seorang pengembang drone telah berhasil membuat drone yang berupa fixed wing yang telah menyelamatkan korban yang hilang di hutan yang mempunyai sensor mendeteksi keberadaan seseorang[2]. Di dalam dunia militer pun drone sangat di butuhkan untuk dalam hal pengintaian musuh, musuh dapat di deteksi dari radiasi infrared, suhu badan, dan parameter yang bias di gunakan untuk menentukan keberadaan manusia[3]. Suhu yang di dapatkan oleh drone bisa melalui pengukuran langsung maupun pengukuran tidak langsung. Pengukuran kontak langsung dengan cara kontak langsung anatara sensor pada drone dengan objek manusia yang di anggap musuh, sedangkan pengukuran kontak tidak langsung adalah pengukuran dengan tanpa secara langsung dengan objek yang di inginkan. Sensor passive infrared receiver adalah sensor yang di dalamnya menggunakan infrared dalam pengukuran. Tetapi tidak sama dengan infrared yang lainnya, sensor PIR ini tidak memancarkan apapun[4]. Sensor ini merespon energi yang di pantulkan energi yang di dapatkan oleh setiap benda yang di deteksi oleh sensor PIR ini sendiri. Di dalam sensor PIR ini juga mempunyai sensor gerak, yang mempunyai bentuk yang kecil, berdaya rendah dan hargnya tergolong murah. Pada alat yang akan di rancang mempunyai dua fungsi yaitu bisa digunakan sebagai pengintai, penyerbuan karena drone quadcopter ini membawa senjata dan mempunyai kamera untuk menentukan musuh. Selain itu drone ini mempunyai fungsi menyemprot untuk lahan pertanian. Sehingga dari segi fungsi yang ada pada drone quadcopter ini bisa membantu tugas prajurit TNI - AD dan membantu warga sipil untuk mengurangi tenaga yang di gunakan petani. Pada perancangan ini adalah pengembangan alat yang telah di kembangkan dari system pendeteksi untuk lansia menggunkan sensor passive infrared (PIR) dan akselerometer yang kemudian data hasil deteksi tersebut dikirimkan secara telemetri dan di tapilkan pada program visual basic[5]. Serta sensor ini dimanfaatkan untuk system peringatan banjir dengan metode telemetri nirkabel menggunakan transceiver nRF24L01+ dimana 
menambahkan reapeter sebagai penambah jarak pengiriman data yang dikirim maupun di terima. Berdasarkan penjelasan tersebut dan hasil penelitian sebelumnya, Irfandi Prayogi,(2019). Di dalam penelitian ini telah di rancang alat pendeteksi keberadaan musuh menggunakan sensor PIR yang datanya di kirimkan secara telemetri drone prinsip kerja pada penelitian ini seperti radio collar namun ada penembahan reapeter untuk memperjauh jarak pengiriman jangkauan pengiriman data.

\section{BAHAN DAN METODE}

Penelitian ini di lakukan untuk memudahkan operator Drone dalam mendeteksi musuh pada saat pengintaian atau pada saat pertempuran.

Metode penelitian yang dilakukan studi literatur dan eksperimen. Penelitian yang dilakukan terfokus pada pengukuran jarak yang di tangkap sensor PIR . Dari hasil tersebut akan disimpulkan jarak koneksi maksimal yang dapat dicapai dan drone quadcopter tersebut digunakan sebagai reapeter untuk menangkap objek yang disebut musuh.

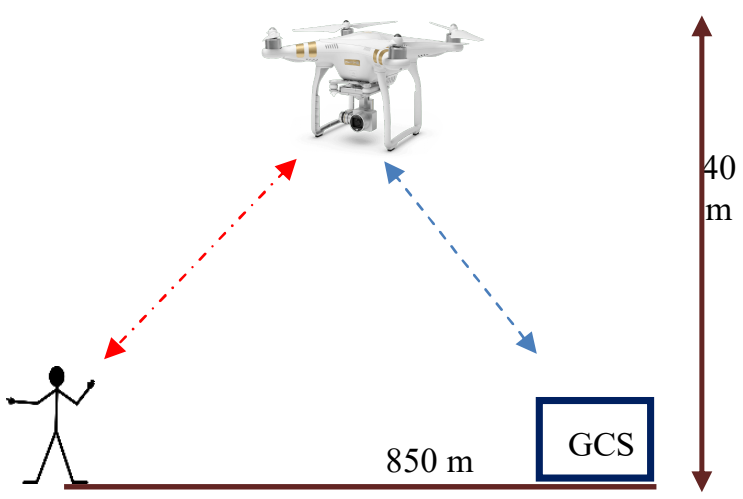

Gambar 1. Diagram alir penelitian.

Merupakan Perancangan alat ini secara menyeluruh dengan menggabungkan rangkaian yang terdiri transmitter, dan receiver yang berjarak $850 \mathrm{~m}$ untuk tinggi drone yang di terbangkan pada ketinggian $40 \mathrm{~m}$. maka jarak maksimum akan bisa terlihat saat data yang dapat dikirim ke receiver.

\section{A. Blok Diagram Telemetri penangkapan objek musuh}

Berikut merupakan gambar blok diagram telemetri penangkapan objek musuh :

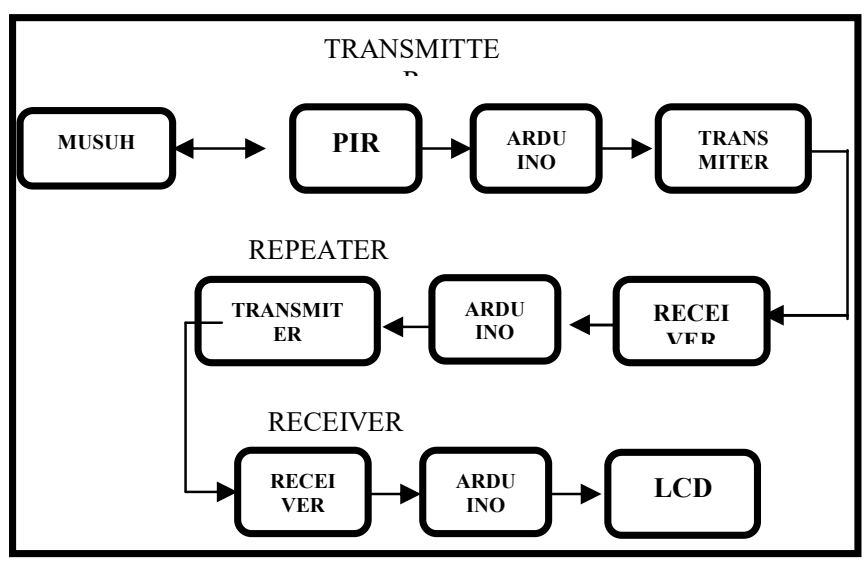

Gambar 2. Blok diagram telemetri

Gambar 2. merupakan blok dari rangkaian sistem penginderaan objek berupa pancaran radiasi pada objek[6]. Output dari modul ini berupa tegangan yang nantinya diproses oleh Arduino Uno lalu data tersebut di kirimkan oleh transmitter. Kemudian data diterima oleh receiver dan di proses lagi oleh Arduino Uno. Data tersebut ditampilkan pada LCD yang berada di GSC[7].

\section{HASIL DAN PEMBAHASAN}

Pengujian alat ini dilaksnakan menjadi lima pengujian. Yaitu pengujian sensor PIR, percobaan setting time sensor, pengujian cangkupan daya pancar sensor, pengujian Transceiver nFRF24L01+ dan percobaan alat secara keseluruhan. Pengujian di laksanakan agar mengetahui kinerja system pada drone quadcopter dapat berjalan dengan baik dan sesuai dengan rencana.

\section{A. Hasil percobaan Sensor PIR}

Hasil dari percobaan yang telah dilakukan . sensor PIR HCSR-05 dapat diketahui kekuatannya dalam mendeteksi radiasi infrared yang dipancarkan suatu objek yang di tangkap melalui drone quadcopter S2GA yang sedang bergerak di udara. Objek percobaan yaitu manusia[. Data hasil dari pengujian pada sensor PIR dapat dilihat pada tabel 1.

tabel 1. Hasil Sensor PIR Objek Manusia.

\begin{tabular}{|c|c|c|}
\hline $\begin{array}{c}\text { Jarak sensor } \\
\text { dengan } \\
\text { Objek }(\mathrm{m})\end{array}$ & $\begin{array}{c}\text { Hasil } \\
\text { Ya/ tidak }\end{array}$ & Buzzer \\
\hline 1 & Ya & Hidup \\
\hline 2 & Ya & Hidup \\
\hline 3 & Ya & Hidup \\
\hline 4 & Ya & Hidup \\
\hline 5 & Ya & Hidup \\
\hline 6 & Ya & Hidup \\
\hline 7 & Ya & Hidup \\
\hline 8 & Ya & Hidup \\
\hline 9 & Ya & Hidup \\
\hline 10 & Ya & Hidup \\
\hline 11 & Ya & Hidup \\
\hline 12 & Tidak & Mati \\
\hline
\end{tabular}

Pada Tabel 1. Dalam percobaan ini, jarak antara sensor dan manusia dari $1 \mathrm{~m}$ sampai dengan 12, dapat diketahui sensor dapat mengangkap gambar objek hanya sampai jarak1 sampai 11 meter. Dan sinyal output pada sensor yang berupa data digital yang dapat mendeteksi adanya radiasi high dan low ketika mendeteksi objek. Sedangkan kuantitas radiasi pancaran pada manusia hanya sampai jarak $11 \mathrm{~m}$.

\section{B. Pengukuran Setting Time Sensor}

Pada saat pengujian di mulai sensor ini aktifkan dengan setting time yang berfungsi mendeteksi pacarana inframerah suatu objek yang berada pada suatu lingkungan atau tempat. Perlunya pengukuran ini adalah untuk mendapatkan waktu yang pas dan tepat agar tidak terjadi permasalahan jika sensor ini bekerja saat dihubungkan dengan rangkaian 
perangkat lain. Output sensor ini dihubungkan dengan buzzer, sehinggak jika sensor ini mendeteksi pancaran infrared maka buzzer berbunyi. Setting time ini menggunakan alat stopwatch, dengan memberikan daya pada sensor ini serta memberikan objek yang di deteksi. Jadi setting time merupakan waktu yang di perlukan saat memulai sumber daya pada sensor sampai dengan buzzer tersebut berbunyi. Dari enam percobaan didapatkan rata rata waktu untuk setting time adalah 30 detik.

\section{Pengukuran Cangkupan Daya Pancar Sensor}

Cangkupan daya pancar yang biasa di sebut coverage. Posisi objek yang di tangkap oleh sensor ini behadapan secara lurus dengan sudut o derajat dengan sensor yang akan bergerak ke kanan dan ke kiri dalam jarak tertentu. Objek yang di pilih dalam percobaan ini adalah manusia . mulai dari titik awal 1 meter objek akan di deteksi samapai jarak 11 meter, sensor ini dapat melakuakan pendeteksian. Pada jarak diatas 11 meter sensor ini sudah tidak bias mendeteksi manusia.

\section{Pengujian Transceiver nFRF24L01+}

Dengan transceiver ini , untuk menguji seberapa jauh jangkauan pengeriman data dari transceiver ke receiver . yang pertama - tama program di upload dan dihubungkan pada baterai. Pengujian ini di lakuakan pada keaadan yang cerah dengan kondisi yang bervariasi yaitu tanpa adanya halangan dan adanya halangan agar dapat kita ketahuai hasil yang bias di capai oleh drone quadcopter S2GA dalam pengiriman data.

Tabel 2. Pengujian Transceiver nFRF24L01

Pada tabel 2. Merupakan Jarak maksimum yang di

\begin{tabular}{|c|c|c|c|}
\hline \multirow{2}{*}{$\begin{array}{c}\text { Kondisi } \\
\text { Keadaan }\end{array}$} & \multicolumn{2}{|c|}{ kode pengiriman } & $\begin{array}{c}\text { Jarak } \\
\text { maksimum } \\
\text { pengiriman } \\
\text { data }\end{array}$ \\
\hline $\begin{array}{c}\text { Cerah tanpa } \\
\text { penghalang }\end{array}$ & Tes jarak & $\begin{array}{c}\text { Tes } \\
\text { jarak }\end{array}$ & $1000 \mathrm{~m}$ \\
\hline $\begin{array}{c}\text { Cerah, ada } \\
\text { penghalang }\end{array}$ & Tes jarak & $\begin{array}{c}\text { Tes } \\
\text { jarak }\end{array}$ & $400 \mathrm{~m}$ \\
\hline
\end{tabular}

dapatkan dalam pengujian transceiver nRF24L01+ adalah $1000 \mathrm{~m}$ dengan tanpa halangan. Data ini sesuai dengan perencanaan yang telah di buat karena sumber daya yang di gunakan memakai sumber daya yang besar sebesar 10000 mAh. Meskipun telah di gunakan beberapa kali penerbangan dan pengiriman data tidak terganggu karena sumber daya yang berkurang.

\section{E. Percobaan Alat Keseluruhan}

Pengujian dari implementasi yang dilakukan menguji jarak maksimal system dapat menangkap objek dan mengirimkan data saat terbang membawa senjata SS2-V2 yang dilakukan di POLTEKAD. Percobaan akhir ini menggabungkan semua komponen -komponen yang sebelumnya terpisah . pada transmitter yang terdapat pada sensor PIR dan receiver dapat di bentangkan antara jarak $850 \mathrm{~m}$ antara sensor PIR dan receiver. Dari percobaan ini juga bahwa dalam jarak 850 tanpa adanya halangan, data yang di kirimkan dan penerimaan berjalan dengan baik. Sedangkan jika adanya halangan seperti pohon dan Gedung drone dengan jarak $850 \mathrm{~m}$ tidak dapat mengirimkan dan menerima data hal ini disebabkan sinyal diserap atau sinyal tidak bisa melewati halangan tersebut.

\section{KESIMPULAN}

Implementasi sistem pendeteksi musuh menggunakan sensor PIR dan di bawa oleh drone quadcopter S2GA telah berhasil. Sistem yang terdiri dari transmitter, reapater, dan receiver. Transmitter merupakan sebagai mengirimkan objek yang telah di deteksi oleh kamera lalu di kirimkan ke reapeter yang berupa drone. Drone ini sebagai penghubung dan penguat sinyal agar data bisa diterima dengan baik pada LCD yang di tampilkan dari GCS. Receiver berfungsi sebagai tempat penerima data hasil pendeteksi sensor yang telah di teruskan dari drone quadcopter S22GA. Sistem telemetri wireless menggunakan transceiver nRF24L01+ berhasil mengirimkan data tanpa adanya penghalang saat melakukan penerbangan sejauh $1 \mathrm{~km}$, jangkauan maksimum ketika ada penghalang sejauh $400 \mathrm{~m}$ dengan cuaca yang cerah dan drone quadcopter S2GA ini telah di operasikan saat pengujian dengan jarak horizontal sejauh $835 \mathrm{~m}$. untuk jarak maksimum vertikalnya $150 \mathrm{~m}$, data ini berdasarkan datasheet drone.

\section{DAFTAR PUSTAKA}

[1] R. A. N. Lema, "Flight Controller Pada Sistem Quadcopter Menggunakan Sensor Imu (Inertial Measurement Unit) Berbasis Mikrokontroller Atmega 2560," Univ. Sanata Dharma, vol. 116, no. 1 , pp. 1-166, 2016.

[2] H. S. Saroinsong et al., "Rancang Bangun Wahana Pesawat Tanpa Awak (Fixed Wing) Berbasis Ardupilot," E-Journal Tek. Elektro Dan Komput., vol. 7, no. 1, pp. 73-84, 2018.

[3] B. Arifin, "Aplikasi Sensor Passive Infra Red (PIR) Untuk Pendeteksian Makhluk Hidup Dalam Ruang," Pros. SNST ke-4, no. 2011, pp. 39-44, 2013.

[4] M. S. Pir, D. Dan, A. Uno, V. Neo-m, S. Pir, and K. Kunci, “6M V2 Modul GPS Ublox Neo 6M V2 merupakan modul GPS yang dapat berkerja dengan mikrokontroler Arduino," pp. 1-6.

[5] I. Prayogi, "Penelitian Menggunakan Sensor PIR dan Drone Berbasis Arduino Uno," vol. 8, no. 2, pp. 99-105, 2019.

[6] J. Teknik, E. Fakultas, and T. Universitas, "TELEMETRI DATA ANTARA UNMANNED AERIAL VEHICLE ( UAV ) DENGAN GROUND CONTROL STATION ( GCS ) H op Time."

[7] R. Hidayat and R. Mardiyanto, "Pengembangan Sistem Navigasi Otomatis Pada UAV (Unmanned Aerial Vehicle) dengan GPS(Global Positioning System) Waypoint," J. Tek. ITS, vol. 5, no. 2 , 2017, doi: 10.12962/j23373539.v5i2.16342. 